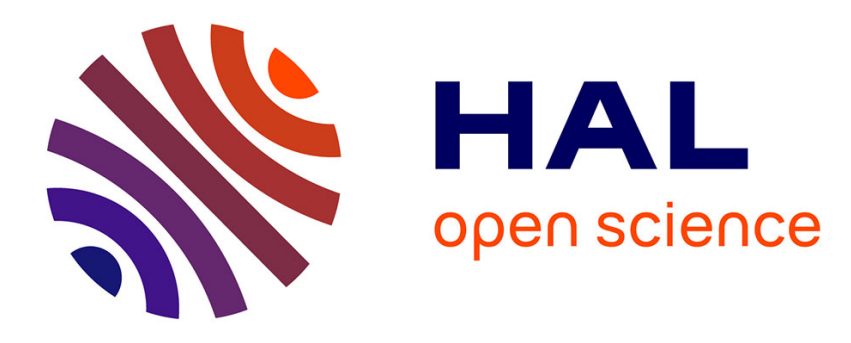

\title{
Optimal Nuclear Waste Burial Policy under Uncertainty
}

Alain Ayong Le Kama, Mouez Fodha

\section{To cite this version:}

Alain Ayong Le Kama, Mouez Fodha. Optimal Nuclear Waste Burial Policy under Uncertainty. 2008. halshs-00348869

\section{HAL Id: halshs-00348869 \\ https://shs.hal.science/halshs-00348869}

Submitted on 22 Dec 2008

HAL is a multi-disciplinary open access archive for the deposit and dissemination of scientific research documents, whether they are published or not. The documents may come from teaching and research institutions in France or abroad, or from public or private research centers.
L'archive ouverte pluridisciplinaire HAL, est destinée au dépôt et à la diffusion de documents scientifiques de niveau recherche, publiés ou non, émanant des établissements d'enseignement et de recherche français ou étrangers, des laboratoires publics ou privés. 


\section{Documents de Travail du Centre d'Economie de la Sorbonne}

C

E

$\mathrm{S}$

W

0

1

k

方

$\mathrm{P}$

a

$\mathrm{p}$

e

$r$

$\mathrm{S}$

Alain Ayong LE KAMA, Mouez FodHA

2008.92 


\title{
Optimal Nuclear Waste Burial Policy under Uncertainty
}

\author{
Alain Ayong Le Kama* Mouez Fodha ${ }^{\dagger}$ \\ July 2008
}

\begin{abstract}
The aim of this paper is to study the optimal nuclear waste burial policy under an uncertainty: the possibility that an accident might occur in the future. The framework is an optimal growth model with pollution disutility. We show, under some conditions on the waste burial policy, that nuclear power may be a long-term solution for the world energy demand. Under uncertainty on the future safety of the buried waste, the social planner will decide to decrease the rate of waste burying, but the evolution of consumption and hence the evolution of the level of buried waste, are ambiguous. Depending on some simple conditions on the balanced growth rate of the economy and on the preference parameters of the households, the optimal amount of buried waste may increase, even if there is a risk of accident in the future.
\end{abstract}

Keywords: Nuclear Waste; Pollution; Growth; Uncertainty.

Jel Class.: D90, Q53

${ }^{*}$ Equippe, Université de Lille 1. E-mail: adayong@univ-paris1.fr.

${ }^{\dagger}$ Corresponding Author. Centre d'Economie de la Sorbonne, Université Paris 1 and PSE. Maison des Sciences Economiques, 106-112 Bld de l'Hôpital, 75013 Paris Cedex. Tel. : +331440782 21. E-mail : fodha@univ-paris1.fr. 


\section{Introduction}

World demand of energy is massively increasing and according to the Intergovernmental Panel on Climate Change, we can expect an increase of the demand of energy of more than $100 \%$ within fifty years. The depletion of the fossil fuel resources and the world fluctuations of the fuel prices led many countries to have recourse to the nuclear energy. Nuclear power can therefore be almost a part of the solution: it reduces the use of fossil energies (coal, oil, gas...); it reduces the Green House Gas emissions; it decreases the risk linked to energy dependence; and finally it protects against volatility of the international prices of resources.

Actually, $75 \%$ of the production of electricity in France is nuclear and several countries have launched nuclear energy programs (like U.K. and Germany). Chakravorty et alii. (2006) show that, under some conditions on the technological process (like major developments in nuclear technology such as fast breeder reactors), the next generation nuclear power may supply significant amounts of clean energy. But, as these authors stated "Without these new nuclear technologies, the problem of waste accumulation becomes critical. Nuclear power may help us reduce atmospheric carbon, but will give rise to a new problem of storing significant amounts of toxic waste". The issue addressed in this paper concerns the management of the increasing nuclear waste stock.

Nuclear activities produce radioactive waste and there is currently no definitive solution for their processing: "The U.S.A. has accumulated some 30000 metric tons of spent fuel rods from power reactors and another 380 000 cubic meters of high-level radioactive waste, a by-product of producing plutonium for nuclear weapons. None of these materials have found anything more than interim accommodation" (Whipple; 1996). Basically, two methods for treatment of nuclear waste exist: Temporary Storage in spent fuel pools and in dry cask storage facilities (France, U.K.) or Final Storage (i.e. burying of waste) in deep geological repositories (U.S.A., Sweden). Governments have 
to choose between temporary or final storage and the decision rule results from a trade-off between the risk of deterioration of waste protections (i.e. diffusion of the radioactivity underground, polluting groundwater) and the benefit resulting from the decrease of the harmfulness of the radioactivity (delay means decay). But these two waste process solutions are not similar in the long-term. In the case of Temporary Storage, present generations suffer the consequences of the nuclear waste proximity. Conversely, in the case of Final Storage (burying), waste disappear underground for several thousand years and may reappear in the future (by accident or not), harming therefore the welfare of future generations.

The aim of this paper is to study the optimal nuclear waste burial policy under an uncertainty: the possibility that an accident might occur in the future, which implies the reappearance of part of the stock previously buried. Two issues are raised in this paper: first, we analyze what should be the optimal burial policy in a deterministic world; secondly, we consider the extent to which an accident changes radically the optimal behavior of the central planner.

Following Hotteling (1931), Dasgupta and Heal (1974) and Hartwick (1977) who analyze the optimal use (exploitation/depletion) of environmental resources ${ }^{1}$, we consider an optimal growth path of an economy facing a dilemma of consumption vs. pollution. The framework introduced in this paper, the Ramsey model, is quite similar to the one uses in the papers dealing with optimal pollution control (van der Ploeg and Withagen; 1991, Gradus and Smulders; 1996, Ayong Le Kama; 2001, Ayong Le Kama and Schubert; 2004, 2006). In these papers, the rate of change of the stock of pollution or of the stock of the environmental resource, that is the natural rate of absorption/regeneration, is given. The framework introduced here is different since we determine endogenously the optimal rate of waste burying, as if the rate of change of the stock of pollution becomes endogenous.

\footnotetext{
${ }^{1}$ See for example Heal (1993) for a survey on these topics.
} 
The model introduced in this paper is very simple. We consider an economy with only one good: nuclear electricity. Its production generates radioactive solid waste. For simplification, we assume that the flow of radioactive waste is proportional to the level of consumption. Consumption and pollution enter in a non-separable way into the utility function. Besides, we assume that the social planner can bury a part of the remaining stock of the radioactive waste in some appropriately deep final geological repositories. Hence, the social planner goal is to choose the optimal waste burial policy.

Following Chakravorty et. alii. (2006), we show, under some conditions on the burial waste policy, that nuclear power may be a long-term solution for the world energy demand. Under uncertainty on the future safety of the buried waste, the social planner will decide to decrease the rate of burying, but the evolution of the consumption and hence of the level of buried waste are ambiguous. Namely (and counter-intuitively), depending on some simple conditions on the balanced growth rate of the economy and on the preference parameters of the households, optimal consumption and then optimal amount of buried waste may increase, even under a risk of accident in the future.

The paper is organized as follows. Section 2 presents the model. Section 3 describes the optimal growth path in the deterministic economy. Section 4 presents the optimal policy under uncertainty. The last section concludes.

\section{The model}

We consider an economy in which there is only one good: nuclear electricity. Let $C_{t}$ be the level of consumption of this good. Its production generates radioactive solid waste. We assume that, at each period $t$, the flow of radioactive waste is proportional to the level of consumption: $\beta C_{t}$, with a constant rate $\beta>0$.

Besides, we assume that at each date $t$, the social planner can bury a part $\gamma_{t}$ of the remaining stock $S_{t}$ of the radioactive waste in some appropriate deep 
final geological repositories. Thus, the evolution of the stock is given by:

$$
\dot{S}=\beta C_{t}-\gamma_{t} S_{t}
$$

where $\left.\left.\gamma_{t} \in\right] 0,1\right]$ measures the time $t$ rate of waste burying, which is chosen endogenously by the central planner, and $\gamma_{t} S_{t}$ is the total stock of waste buried at time $t$.

For simplification, we also assume that the production of the nuclear electricity $Y_{t}$ is exogenously given and grows at a constant rate $r^{2}$. We then have $\frac{\dot{Y}}{Y}=r$, and at each date $t: Y_{t}=Y_{0} e^{r t}$, with the initial value $Y_{0}$ which is given.

Thus, at each date $t$, the social planner faces the following budgetary constraint:

$$
C_{t}+a \gamma_{t} S_{t} \leq Y_{t}
$$

where $a$ is the unitary cost of burying waste. Because time $t$ total income is given, there is a permanent trade-off between consumption and burying of waste. Any unit of income which is used for final storage is no longer available for consumption.

At time $t$ the representative household derives utility from the consumption of electricity at a level $C_{t}$, but his utility is depleted by the stock of nuclear waste $S_{t}$. The utility function $U(C, S)$ is assumed to be strictly concave, twice continuously differentiable and to possess the following properties.

Assumption 1: $U_{C}^{\prime}(C, S)>0 ;{ }^{3} U_{C C}^{\prime \prime}(C, S)<0 ; U_{S}^{\prime}(C, S)<0 ; U_{S S}^{\prime \prime}(C, S)<$ 0 ; and also $U_{C S}^{\prime \prime}(C, S)>0 .^{4}$

\footnotetext{
${ }^{2}$ Because there is only one good in this economy, the production $Y_{t}$ is equal to the total income.

${ }^{3} U_{C}^{\prime}$ and $U_{S}^{\prime}$ are the first partial derivatives of the function $U($.$) with respect to its$ arguments $C$ and $S . U_{C C}^{\prime \prime}$ is likewise the second partial derivative, using obvious notation.

${ }^{4}$ We assume that the marginal utility of consumption increases with the stock of radioactive waste: utility exhibits a 'compensation' effect, in the terminology of Michel and Rotillon (1995).
} 
Let us denote: $\varepsilon=\frac{S U_{S}^{\prime}}{C U_{C}^{\prime}}$, which stands for the "relative disutility of the radioactive stock"; $\eta_{1}=\frac{C U_{C C}^{\prime \prime}}{U_{C}^{\prime}}$, the elasticity of the marginal utility with respect to consumption; $\eta_{2}=\frac{S U_{C S}^{\prime \prime}}{U_{C}^{\prime}}$, the elasticity of the marginal utility of consumption with respect to the stock of radioactive waste; and $\eta_{3}=\frac{S U_{S S}^{\prime \prime}}{U_{S}^{\prime}}$, the elasticity of the marginal disutility of the waste stock.

Thus, the feasibility of a balanced growth path (BGP), that is the case where the rate of growth of the consumption and the stock is constant for a given $\gamma$ (see below), yields the following:

Assumption 2: $(i) \eta_{1}, \eta_{2}, \eta_{3}$ and $\varepsilon$ are constants ${ }^{5}$; $(i i)$ for the concavity of the utility function, we also need $\eta_{3}>0\left(i e . \eta_{2}>1\right)$ and $\eta_{1}+\eta_{2}>0$; (iii) and for simplicity we also assume $\varepsilon<-1 .^{6}$

\section{The optimal decision rule in the determin- istic case}

The social planner chooses the optimal waste burial policy by maximizing the discounted sum of welfare:

$$
P(1) \quad\left\{\begin{array}{l}
\max _{\{C, \gamma\}} W\left(S_{0}\right)=\int_{0}^{\infty} U(C, S) e^{-\delta t} d t \\
\text { s.t. } \quad \begin{array}{l}
\quad \begin{array}{l}
S=\beta C-\gamma S \\
\end{array} \\
\quad S \geqslant 0 \gamma S \leq Y
\end{array}
\end{array}\right.
$$

where $\delta>0$ is the exogenous discount rate.

The current value Hamiltonian is:

$$
H=U(C, S)+\lambda(\beta C-\gamma S)+\mu(Y-C-a \gamma S)
$$

\footnotetext{
${ }^{5}$ Gradus and Smulders (1996) or Michel and Rotillon (1996) show that condition (ii) is a necessary condition for the existence of a balanced growth path when respectively the stock of environmental quality is a source of utility or the one of pollution affects the utility.

${ }^{6}$ More generally, one just needs $\varepsilon<0$. Even if these elasticities are constant, they are not independant. We have $\eta_{3}=\eta_{2}-1>0$ implying that $\eta_{2}>1$.
} 
where $\lambda<0$ is the shadow cost of waste stock and $\mu \geq 0$ is the shadow price of aggregate income or its marginal utility.

The first order necessary conditions are:

$$
\begin{cases}(i) & \frac{\partial H}{\partial C}=0 \Leftrightarrow \frac{1}{\beta}\left(U_{C}^{\prime}-\mu\right)=-\lambda \\ (i i) & \frac{\partial H}{\partial \gamma}=0 \Leftrightarrow a \mu=-\lambda \\ (i i i) & \dot{\lambda}=\delta \lambda-\frac{\partial H}{\partial S} \Leftrightarrow \frac{\dot{\lambda}}{\lambda}=\delta-\frac{U_{S}^{\prime}}{\lambda} \\ (i v) & \mu(Y-C-a \gamma S)=0 \\ (v) & \frac{\dot{S}}{S}=\beta \frac{C}{S}-\gamma\end{cases}
$$

The necessary condition $(i)$ of (4) states that the social planner will choose an optimal decision in this deterministic case such that the shadow cost of the waste stock is proportional to the difference between the marginal utility of consumption and the one of the income, with a coefficient $\frac{1}{\beta}, \beta$ being the rate at which the waste stock changes with consumption. We find here once again this permanent trade-off between consumption and burying of waste described above. This relation also shows that when the social planner decides to bury a unit of the stock there will be two different effects. The first effect is because the income is given, the level of consumption will automatically decrease and also the utility. But, on the other hand because the stock of waste decreases its disutility will also go down. With the necessary condition ( $i i)$ of (4), we obtain that this shadow cost of the waste stock is also proportional to the the shadow price of the income, but now with a coefficient equal to the unitary cost of burying. This condition also shows in the reverse that, given that $\lambda<0$, then $\mu>0$. Thus the budgetary constraint (2) is always binding. ${ }^{7}$ Condition ( $\left.i i i\right)$ of (4) gives the growth rate of this shadow cost.

Using conditions (i) and (ii) of (4), condition (iii) becomes:

$$
\frac{\dot{\lambda}}{\lambda}=\delta+\frac{1+a \beta}{a} \varepsilon \frac{C}{S}
$$

\footnotetext{
${ }^{7}$ For simplification, we will assume in the rest of the paper that this condition is always fulfilled.
} 
Besides, by differentiating the first optimality condition (i) of (4) and using (5), we easily find the growth rate of consumption:

$$
\frac{\dot{C}}{C}=-\frac{1}{\eta_{1}}\left[-\delta+\eta_{2} \frac{\dot{S}}{S}-\frac{1+a \beta}{a} \varepsilon \frac{C}{S}\right]
$$

Let us define the ratio of the consumption to the nuclear waste stock $x=\frac{C}{S}$. The previous equation, together with the law of motion of the stock (1), give the following:

$$
\frac{\dot{x}}{x}=\frac{1}{\eta_{1}}\left(\delta+\left[\frac{1+a \beta}{a} \varepsilon-\left(\eta_{2}+\eta_{1}\right) \beta\right] x+\left(\eta_{1}+\eta_{2}\right) \gamma\right)
$$

Now, knowing that by assumption $\frac{\dot{Y}}{Y}=r$, by differentiating (eq. 2) we find the following growth rate of the rate of waste burying:

$$
\frac{\dot{\gamma}}{\gamma}=\left(r-\frac{\dot{S}}{S}\right) \frac{Y}{a \gamma S}-\frac{x}{a \gamma} \frac{\dot{x}}{x}
$$

Then the three dimensions dynamic system characterizing the evolution of the economy is given by:

$$
\begin{cases}(i) & \frac{\dot{x}}{x}=\frac{1}{\eta_{1}}\left(\delta+\left[\frac{1+a \beta}{a} \varepsilon-\left(\eta_{2}+\eta_{1}\right) \beta\right] x+\left(\eta_{1}+\eta_{2}\right) \gamma\right) \\ (i i) & \frac{\dot{S}}{S}=\beta x-\gamma \\ (i i i) & \frac{\dot{\gamma}}{\gamma}=\left(r-\frac{\dot{S}}{S}\right) \frac{Y}{a \gamma S}-\frac{x}{a \gamma} \frac{\dot{x}}{x}\end{cases}
$$




\section{The stationary solution}

Let us find a balanced growth $\operatorname{path}^{8}$ (BGP), $\left(x^{*}, S^{*}, \gamma^{*}\right)$ of the three dimensions dynamic system (8), where the optimal level of consumption and the one of the waste stock grow at the same constant rate as the income, $r$, and the rate of waste burying is constant, that is: $\frac{\dot{x}}{x}=\frac{\dot{\gamma}}{\gamma}=0$ and $\frac{\dot{S}}{S}=\frac{\dot{C}}{C}=\frac{\dot{Y}}{Y}=r$.

By using equation $(i)$ and $(i i)$ of (8), we easily obtain stationary values of the ratio $x$ :

$$
x^{*}=\frac{a}{(1+a \beta) \varepsilon}\left[\left(\eta_{2}+\eta_{1}\right) r-\delta\right]
$$

This leads to the following.

Proposition 1 . Under assumptions 1 and 2 , there is a unique $B G P\left(x^{*}, S^{*}, \gamma^{*}\right)$ solution of the deterministic problem $P(1)$ iff the parameters of the economy satisfy:

$$
\left(\eta_{2}+\eta_{1}\right) r-\varepsilon\left(1+\frac{1}{a \beta}\right) r>\delta>\left(\eta_{2}+\eta_{1}\right) r .
$$

This solution is such that:

$$
\begin{cases}(i) & x^{*}=\frac{a}{(1+a \beta) \varepsilon}\left[\left(\eta_{2}+\eta_{1}\right) r-\delta\right] \\
(i i) & \gamma^{*}=\beta x^{*}-r \\
(\text { iii }) & \begin{array}{l}
S_{t}^{*}=S_{0}^{*} e^{r t} ; C_{t}^{*}=x^{*} S_{0}^{*} e^{r t} ; \text { with } S_{0}^{*}=\frac{Y_{0}}{(1+a \beta) x^{*}-a r} \\
\lambda_{t}^{*}=\lambda_{0}^{*} e^{\left(\eta_{2}+\eta_{1}\right) r t} ; \text { with } \lambda_{0}^{*}=-\frac{a}{1+a \beta} U_{C}^{\prime}\left(x^{*} S_{0}^{*}, S_{0}^{*}\right) \\
\text { and } \mu_{t}^{*}=-\frac{\lambda_{t}^{*}}{a} \forall t .
\end{array}\end{cases}
$$

Proof. We know by assumption 2 (ii) that $\left(\eta_{2}+\eta_{1}\right)>0$ and (iii) that $\varepsilon<-1$, then we have $x^{*}>0$ iff $\left(\eta_{2}+\eta_{1}\right) r<\delta$; this gives the RHS of

\footnotetext{
${ }^{8}$ We can first notice that there is no stationnary solution $\left(x^{*}, S^{*}, \gamma^{*}\right)$ of the three dimensions dynamic system (8) with $\frac{\dot{x}}{x}=\frac{\dot{S}}{S}=\frac{\dot{\gamma}}{\gamma}=0$, that is with $x^{*}, S^{*}$ and $\gamma^{*}$ constants. To see this, let us first take equation (ii) of (8), if $\frac{\dot{S}}{S}=0=\beta x-\gamma$, then $\gamma=\beta x$. Now, if we have $\frac{\dot{x}}{x}=0$, that is if $x$ is constant, we may also have $\gamma$ constant. But, by using equation (iii), we can easily see that when $\frac{\dot{x}}{x}=\frac{\dot{S}}{S}=0$, then $\frac{\dot{\gamma}}{\gamma}=r \frac{Y_{0} e^{r t}}{a \gamma S}>0$, thus $\gamma_{t}$ cannot be constant if $S$ is also constant.
} 
condition (10). Now, we have $\gamma^{*}>0$ iff $\left(\eta_{2}+\eta_{1}\right) r-\varepsilon\left(1+\frac{1}{a \beta}\right) r>\delta$; which is the LHS of the same condition.

Besides, knowing the values of $x^{*}$ and $\gamma^{*}$, it is easy to find the optimal paths of waste stock and consumption. Let us first find the initial value of the waste stock $S_{0}$, as a function of the given initial income $Y_{0}$. Knowing that $Y_{t}=C_{t}^{*}+a \gamma^{*} S_{t}^{*}=\left(x^{*}+a \gamma^{*}\right) S_{t}^{*}=\left((1+a \beta) x^{*}-a r\right) S_{t}^{*}$ and that along the BGP $\frac{\dot{S}}{S}=\frac{\dot{Y}}{Y}=r$, we can deduce that: $S_{0}^{*}=\frac{Y_{0}}{(1+a \beta) x^{*}-a r}$. We then have: $S_{t}^{*}=S_{0}^{*} e^{r t}$ for the waste stock; $C_{t}^{*}=x^{*} S_{0}^{*} e^{r t}$ for consumption; and also, by using (5), $\lambda_{t}^{*}=\lambda_{0}^{*} e^{\left(\eta_{2}+\eta_{1}\right) r t}$ with $\lambda_{0}^{*}=-\frac{a}{1+a \beta} U_{C}^{\prime}\left(x^{*} S_{0}^{*}, S_{0}^{*}\right)$, for the shadow cost of the waste stock and, with (4) (ii) we obtain $\mu_{t}^{*}=-\frac{\lambda_{t}^{*}}{a} \forall t$, for the shadow price of the aggregate income.

This proposition states the following for the deterministic solution, under assumptions 1 and 2 and condition (10), which gives bounds on the discount rate so as to obtain a BGP. First, if the discount rate increases, that is if the social planner is more impatient, the ratio $x^{*}$ and also the optimal rate of burying $\gamma^{*}$ will increase also $\frac{\partial \gamma^{*}}{\partial \delta}=\beta \frac{\partial x^{*}}{\partial \delta}>0$. Besides, if it is the growth rate of the economy $r$ which increases, $x^{*}$ and $\gamma^{*}$ will both decrease, we have $\frac{\partial x^{*}}{\partial r}<0$ and $\frac{\partial \gamma^{*}}{\partial r}=\beta \frac{\partial x^{*}}{\partial r}-1<0$.

\section{The optimal valuation of the waste stock}

Moreover, knowing the values of $x^{*}, S^{*}$ and $\gamma^{*}$ along the BGP, we can now find the optimal value of the objective function, that is the optimal valuation of the initial waste stock in the deterministic case: $W\left(S_{0}^{*}\right)=$ $\int_{0}^{\infty} U\left(x^{*} S_{0}^{*} e^{r t}, S_{0}^{*} e^{r t}\right) e^{-\delta t} d t$

To obtain an analytical value of this valuation, we can specify, without any loss of generality, a utility function of the CES form, suitable with assumptions 1 and 2:

$$
U(C, S)={\frac{\left(C S^{\varepsilon}\right)^{1-\frac{1}{\sigma}}}{1-\frac{1}{\sigma}}}
$$

where $0<\sigma<1$ denotes the intertemporal elasticity of substitution for 
consumption. We then have in this case $U()<$.0 and bounded from above, $\eta_{1}=-\frac{1}{\sigma}<0, \eta_{2}=\varepsilon\left(1-\frac{1}{\sigma}\right)=\varepsilon\left(1+\eta_{1}\right)>0$ (by assumption to still have the "compensation effect", that is why we need $\sigma<1$, given that $\varepsilon<-1$, this assumption $(\sigma<1)$ is also sufficient in this case to ensure the concavity of $U()$.$) and \eta_{3}=\eta_{2}-1$.

Within this utility function, we show (see Appendix A (i)) that the optimal valuation of the initial waste stock in the deterministic case is:

$$
W\left(S_{0}^{*}\right)=B U\left(x^{*} S_{0}^{*}, S_{0}^{*}\right)
$$

with $B=\frac{-1}{r\left(1-\frac{1}{\sigma}\right)(1+\varepsilon)-\delta}=\frac{-1}{r\left(1+\eta_{1}+\eta_{2}\right)-\delta}$ which is assumed to be positive, such that the valuation of the ("bad") waste stock being negative. This implies the following additional condition on the parameters of the economy: $\delta>$ $r\left(1+\eta_{1}+\eta_{2}\right)=r+r\left(\eta_{1}+\eta_{2}\right)$. Combining this condition with the one of the existence of a stationary state given (10), we obtain a more restrictive condition:

$$
\left(\eta_{2}+\eta_{1}\right) r-\varepsilon\left(1+\frac{1}{a \beta}\right) r>\delta>r+r\left(\eta_{1}+\eta_{2}\right)
$$

\section{The optimal waste burial policy under un- certainty}

We assume that there is a possibility that at a given future date $T$, an accident occurs with a probability $p \in[0,1]$ which implies the destocking of a quantity $\bar{S}$. For simplification, we also assume that this quantity is proportional to the existing waste stock $\bar{S}=\theta S_{T}^{(3)}$, where $S_{T}^{(3)}$ is the level of the remaining waste stock just before the accident occurs and $\theta \geq 0$. Besides, we assume that the destocking is a once and for all phenomenon. Thus the level of the waste stock just after the accident has occurred, $S_{T}^{(2)}$, is given by:

$$
S_{T}^{(2)}= \begin{cases}\tilde{S}_{T}^{(2)}=(1+\theta) S_{T}^{(3)} & \text { with probability } p \\ S_{T}^{(3)} & \text { with proba. } 1-p\end{cases}
$$


thus, with the probability $p$, the stock after time $T$ will be the one remaining before the accident plus a part $\theta$ and with a probability $(1-p)$ this stock will remain as before the accident.

\subsection{The model after the occurrence of the nuclear ac- cident}

After the nuclear waste stock accident has occurred, the problem is the same as the one of certainty $P(1)$, the only difference is the initial level of the radioactive waste stock.

The state valuation function of a given remaining stock $S_{T}^{(2)}$ from time $T$ onwards is therefore given as follows:

$$
P(2) \quad\left\{\begin{array}{l}
\max _{\left\{\gamma_{t}^{(2)}\right\}} W\left(S_{T}^{(2)}\right)=\int_{T}^{\infty} U\left(C_{t}^{(2)}, S_{t}^{(2)}\right) e^{-\delta(t-T)} d t \\
\text { s.t. } \quad \begin{array}{l}
\dot{S}^{(2)}=\beta C^{(2)}-\gamma^{(2)} S^{(2)} \\
C^{(2)}=Y-a \gamma^{(2)} S^{(2)} \\
S_{t}^{(2)}, C_{t}^{(2)}, \gamma^{(2)} \geqslant 0, \quad \forall t \geqslant T \\
Y_{T} \text { given }
\end{array}
\end{array}\right.
$$

By analogy, with the solution of the problem $P(1)$ above, we know that the economy will keep the same growth path, with $x^{(2)}=x^{*}$ and $\gamma^{(2)}=\gamma^{*}$. It inherits a level of the waste stock $S_{T}^{(2)}$, and depending on this stock, that is on the realization of the uncertainty (the occurrence of the accident), we also obtain the following along the new BGP from time $T$ onwards: $\frac{\dot{C}_{t}^{(2)}}{C_{t}^{(2)}}=\frac{\dot{S}_{t}^{(2)}}{S_{t}^{(2)}}=r ; S_{t}^{(2)}=S_{T}^{(2)} e^{r(t-T)} ; C_{t}^{(2)}=x^{*} S_{t}^{(2)} \forall t=[T,+\infty[$.

\subsection{The model with uncertainty}

As we have assumed that there is a possibility that at a given future date $T$, an accidental destocking occurs which changes the waste stock in an unknown 
level, the program of the social planner writes (see Dasgupta and Heal; 1974):

$$
P(3)\left\{\begin{array}{l}
\max _{\left\{\gamma_{t}^{(3)}\right\}} \int_{0}^{T} U\left(C_{t}^{(3)}, S_{t}^{(3)}\right) e^{-\delta t} d t+e^{-\delta T} E W\left(S_{T}^{(2)}\right) \\
\text { s.t. } \quad \begin{array}{l}
\dot{S}^{(3)}=\beta C^{(3)}-\gamma^{(3)} S^{(3)} \\
C^{(3)}=Y-a \gamma^{(3)} S^{(3)} \\
S_{t}^{(3)}, C_{t}^{(3)}, \gamma^{(3)} \geqslant 0, \quad \forall t \geqslant T \\
Y_{0} \text { given }
\end{array}
\end{array}\right.
$$

where the mathematical expectation of the remaining stock at time $T$, just after the accident has occurred, i.e. the expected negative bequest for the future generations is

$$
E W\left(S_{T}^{(2)}\right)=p W\left(\tilde{S}_{T}^{(2)}\right)+(1-p) W\left(S_{T}^{(3)}\right)
$$

The first order necessary conditions of this problem $P(3)$ are the same as those of the one of the deterministic case $P(1)$, that is when there is no accident. The dynamic system, in $\left(x^{(3)}, S^{(3)}, \gamma^{(3)}\right)$, characterizing the evolution of the economy before the accident occurs is then still (8). However, we must add the following transversality condition:

$$
\lambda_{T}^{(3)}=\frac{\partial E W\left(S_{T}^{(2)}\right)}{\partial S_{T}^{(2)}}
$$

This transversality condition states that when the accident occurs, the shadow cost of the waste stock must be equal to the expected marginal negative value of the remaining (existing) stock.

We first know from the first order conditions (4) that $\lambda_{T}^{(3)}=-\frac{U_{C}^{\prime}\left(x^{(3)} S_{T}^{(3)}, S_{T}^{(3)}\right)-\mu_{T}^{(3)}}{\beta}$, with $\mu_{T}^{(3)}=-\frac{\lambda_{0}^{(3)}}{a} e^{\left(\eta_{1}+\eta_{2}\right) r T}$. We also show (see Appendix A $\left.(i i)\right)$, by using the utility function given in (12), that $\frac{\partial W\left(\tilde{S}_{T}^{(2)}\right)}{\partial \tilde{S}_{T}^{(2)}}=B[1+\varepsilon] x^{*} U_{C}^{\prime}\left(x^{*} \tilde{S}_{T}^{(2)}, \tilde{S}_{T}^{(2)}\right)$, when the accident occurs at time $T$, and $\frac{\partial W\left(S_{T}^{(3)}\right)}{\partial S_{T}^{(3)}}=B[1+\varepsilon] x^{*} U_{C}^{\prime}\left(x^{*} S_{T}^{(3)}, S_{T}^{(3)}\right)$ when there is no accident at this time. Knowing also that by assumption 
$\tilde{S}_{T}^{(2)}=(1+\theta) S_{T}^{(3)}$, the RHS of $(16)$, that is the expected marginal value of the waste stock at time $T$, is given by:

$$
\frac{\partial E W\left(S_{T}^{(2)}\right)}{\partial S_{T}^{(2)}}=B[1+\varepsilon] x^{*}\left[p U_{C}^{\prime}\left(x^{*}(1+\theta) S_{T}^{(3)},(1+\theta) S_{T}^{(3)}\right)+(1-p) U_{C}^{\prime}\left(x^{*} S_{T}^{(3)}, S_{T}^{(3)}\right)\right]
$$

and the transversality condition (16) therefore becomes:

$$
-\frac{U_{C}^{\prime}\left(x^{(3)} S_{T}^{(3)}, S_{T}^{(3)}\right)}{\beta}-\frac{\lambda_{0}^{(3)}}{a \beta} e^{\left(\eta_{1}+\eta_{2}\right) r T}=\frac{\partial E W\left(S_{T}^{(2)}\right)}{\partial S_{T}^{(2)}}
$$

\section{The stationary solution}

Knowing the solution of the problem $P(1)$ above, to show that there is a unique solution to this problem $P(3)$ with uncertainty, we only have to show that there exists a unique value $x^{(3)}$ satisfying this transversality condition. This leads to the following.

Proposition 2 . Under assumptions 1 and 2 and given condition (13), there is a unique $B G P\left(x^{(3)}, S^{(3)}, \gamma^{(3)}\right)$ solution of the problem with uncertainty $P(3)$, which is such that :

$$
\begin{cases}(i) \quad x^{(3)}=x^{*}\left[1-[1+\varepsilon] B \beta x^{*} p\left[(1+\theta)^{\left(\eta_{2}+\eta_{1}\right)}-1\right]\right]^{\frac{1}{\eta_{1}}} \\
(i i) \quad \gamma^{(3)}=\beta x^{(3)}-r \\
\left.\quad \begin{array}{l}
S_{t}^{(3)}=S_{0}^{(3)} e^{r t} ; C_{t}^{(3)}=x^{(3)} S_{0}^{(3)} e^{r t} ; \forall t \in[0, T] \\
\text { with } S_{0}^{(3)}=\frac{Y_{0}}{(1+a \beta) x^{(3)}-a r} \\
\lambda_{t}^{(3)}=\lambda_{0}^{(3)} e^{\left(\eta_{2}+\eta_{1}\right) r t} \text { and } \mu_{t}^{(3)}=-\frac{\lambda_{t}^{(3)}}{a} \forall t \in[0, T] \\
\text { with } \lambda_{0}^{(3)}=-a \beta\left(B[1+\varepsilon] x^{*}+\frac{1}{\beta}\right)^{\prime} U_{C}^{\prime}\left(x^{(3)} S_{0}^{(3)}, S_{0}^{(3)}\right.
\end{array}\right)\end{cases}
$$

Proof. First, as we have seen, the necessary conditions are the same in problems $P(1)$ and $P(3)$, apart from the transversality condition (18). We 
also know that this transversality condition must hold for any value of the probability $p$ between 0 and 1 . Besides, if $p=0$, as in the deterministic case, the optimal choice of the social planner will be to choose $x^{(3)}=x^{*}$. Thus, setting $p=0$ and $x^{(3)}=x^{*}$ in (18) allows us to find the value of the initial shadow cost of the waste stock (see Appendix B for details): $\lambda_{0}^{(3)}=$ $-a \beta\left(B[1+\varepsilon] x^{*}+\frac{1}{\beta}\right) U_{C}^{\prime}\left(x^{(3)} S_{0}^{(3)}, S_{0}^{(3)}\right)$.

Now, reintroducing this value of $\lambda_{0}^{(3)}$, which depends on the distribution of probability of an accident only by the level of the initial marginal utility of consumption, in the transversality condition (18) and using the utility function given in (12), we easily show, after few manipulations, that: $x^{(3)}=$ $x^{*}\left[1-[1+\varepsilon] B \beta x^{*} p\left[(1+\theta)^{\left(\eta_{2}+\eta_{1}\right)}-1\right]\right]^{\frac{1}{\eta_{1}}}$. We therefore can obtain the optimal value of the rate of waste burying: $\gamma^{(3)}=\beta x^{(3)}-r$. Also, with the same routine that we used before (see the Proof of proposition 1), we can compute the optimal path of consumption and waste stock before the accident occurs.

\section{A comparison with the deterministic solution}

We now come to one of the main motivation of this paper: will the uncertainty change the behavior of the central planner in a trivial and intuitive way? The common sense would tell us that burying should decrease with the risk of an accident.

Let us rewrite the optimal level of the ratio $x$ in the case of uncertainty, given in equation $(i)$ of $(19)$ as follows:

$$
\left(\frac{x^{(3)}}{x^{*}}\right)^{\eta_{1}}=1-\underbrace{[1+\varepsilon] B \beta x^{*} p}_{-} \underbrace{\left[(1+\theta)^{\left(\eta_{1}+\eta_{2}\right)}-1\right]}_{+}>1
$$

we see that we always have $x^{*} \geqslant x^{(3)}$ and given the relation between $x$ and $\gamma$ in both case, $\gamma=\beta x-r$, we also have $\gamma^{(3)}<\gamma^{*}$. So, as the common sense tell us, the introduction of uncertainty would lead to a choice of a lower rate 
of waste burying. The social planner chooses to limit the largeness of the accident.

But, we also know that, at any time $t$, along these two BGP, the one with uncertainty and the one without, because the level of income is exogenously given, the level of the waste stock is a decreasing function of the ratio $x$ : $S_{t}=\frac{Y_{t}}{(1+a \beta) x-a r}$. The introduction of uncertainty leads to a higher accumulation of the nuclear waste, that is to a higher level of the waste stock. This corresponds to a higher disutility for the household.

Because the introduction of uncertainty does not change the rate of burying and the level of the stock in the same direction, its effect on the evolution of the optimal consumption is not trivial. Basically, we have the static budget constraint $Y=C+a \gamma S$ which implies:

$$
d C=-\left(\begin{array}{c}
d \gamma+d S \\
-
\end{array}\right)
$$

When the rate of burying decreases and, in the same time, the stock of waste increases, the evolution of the flow of buried waste $\gamma S$, and also the one of the total cost of burying $a \gamma S$, and therefore the one of the optimal consumption will depend on the relative change of the two variables. And the determinants of this trade-off are those of the optimal burying rate $\left({ }_{-} \delta, p, \theta, r, a, \varepsilon, \sigma\right)$. This property on the opposite evolution of $\gamma$ and $S$ implies that the total amount of buried waste is also ambiguous. So, even if the social planner faces an uncertainty on the safety of the burial policy, the total amount of buried waste may increase.

\section{Conclusion}

The issue addressed in this paper concerns the management of the increasing nuclear waste stock. We analyze the optimal nuclear waste burial policy under an uncertainty: the possibility that an accident might occur in the future. In a simple optimal growth framework, we consider two waste process 
solutions: temporary storage or burying of waste. We show, under some conditions on the waste burial policy, that nuclear power may be a long-term solution for the world energy demand. This solution consist in burying a constant part of the waste stock, in the deterministic case as well as in the uncertain case. Under uncertainty on the future safety of the buried waste, the social planner will decide to decrease the rate of waste burying, but the evolution of consumption and hence of the level of buried waste are ambiguous. Namely (and counter-intuitively), depending on some simple conditions on the balanced growth rate of the economy and on the preferences parameters of the households, optimal consumption, and then optimal amount of buried waste, may increase even under a risk of accident in the future.

\section{References}

Ayong Le Kama A., (2001) "Preservation and exogenous uncertain future preferences", Economic Theory, vol. 18, pp. 745-752.

Ayong Le Kama A., Schubert K., (2004), "Growth, Environment and Uncertain Future Preferences", Environmental and Resource Economics, 28, p. $31-53$.

Ayong Le Kama A., Schubert K., (2006), "Ressources renouvelables et incertitude sur les préférences des générations futures", Revue d'Economie Politique, $\mathrm{n}^{\circ} 2$, pp. 229-250.

Chakravorty U., Magne B., Moreaux M., (2006), "Can Nuclear Power solve the Global Warming Problem?", IDEI Working Paper, 381.

Dasgupta P.S., Heal G., (1974), "The Optimal Depletion of Exhaustible Resources", Review of economic studies, vol. 41, p. 1-28.

Gradus S., Smulders S., (1996), "Pollution Abatement and Long-term Growth", European Journal of Political Economy, 12, p. 505-532. 
Hartwick J., (1977), "Intergenerational Equity and the Investing of Rents from Exhaustible Resources", American Economic Review, 67, p. 972-974.

Heal G. M., (1993), "The Optimal Use Of Exhaustible Resources", in Handbook of Natural Resource and Energy Economics, vol. III, A.V. Kneese and J.L. Sweeney (Eds), Elsevier Science Publishers.

Hotteling H., (1931), "The Economics of Exhaustible Resources", The Journal of Political Economy, vol. 39, n², p. 137-175.

Michel P., Rotillon G., (1995), "Disutility of Pollution and Endogenous Growth", Environmental and Resource Economics, vol. 6(3), p. 279-300.

Van der Ploeg F., Withagen C., (1991), "Pollution Control and the ramsey Problem", Environmental and Resource Economics, 1, p. 215-236.

Whipple C.G. (1996), "Can Nuclear Waste Be Stored at Yucca Mountain?", Scientific American, vol. 274, p. 72-80.

\section{Appendix}

\section{A The optimal valuation of the initial waste stock}

(i) In the deterministic problem $P(1)$, we know that consumption and the waste stok grow at the same rate $r$, their ratio is constant at the level $x^{*}$ and the optimal rate of burying $\gamma^{*}$ is also constant. Thus, given the utility function specifies in (12), we can write:

$$
\begin{aligned}
W\left(S_{0}^{*}\right) & =\int_{0}^{\infty} U\left(x^{*} S_{0}^{*} e^{r t}, S_{0}^{*} e^{r t}\right) e^{-\delta t} d t \\
& =\frac{U\left(C_{0}^{*}, S_{0}^{*}\right)}{r\left(1-\frac{1}{\sigma}\right)+\varepsilon r\left(1-\frac{1}{\sigma}\right)-\delta}\left[e^{\left(r\left(1-\frac{1}{\sigma}\right)(1+\varepsilon)-\delta\right) t}\right]_{0}^{\infty} \\
& =B U\left(x^{*} S_{0}^{*}, S_{0}^{*}\right)
\end{aligned}
$$


with $B=\frac{-1}{r\left(1-\frac{1}{\sigma}\right)(1+\varepsilon)-\delta}=\frac{-1}{r\left(1+\eta_{1}+\eta_{2}\right)-\delta}>0$ (by assumption). We can also notice that this value is finite.

(ii) Now, given the value $W\left(S_{0}^{*}\right)$, we can deduce the marginal intertemporal welfare, that is the marginal valuation of the initial waste stock:

$$
\frac{\partial W\left(S_{0}^{*}\right)}{\partial S_{0}^{*}}=B[1+\varepsilon] x^{*} U_{C}^{\prime}\left(x^{*} S_{0}^{*}, S_{0}^{*}\right)<0
$$

Thus we can deduce the marginal valuations of the stock remaining after the occurence of the accident in both case with and without a change of the stock. By analogy with the previous result, we have:

$$
\left\{\begin{array}{l}
\frac{\partial W\left(\tilde{S}_{T}^{(2)}\right)}{\partial \tilde{S}_{T}^{(2)}}=B[1+\varepsilon] x^{*} U_{C}^{\prime}\left(x^{*} \tilde{S}_{T}^{(2)}, \tilde{S}_{T}^{(2)}\right) ; \text { if the accident occurs } \\
\frac{\partial W\left(S_{T}^{(3)}\right)}{\partial S_{T}^{(3)}}=B[1+\varepsilon] x^{*} U_{C}^{\prime}\left(x^{*} S_{T}^{(3)}, S_{T}^{(3)}\right) ; \text { if not }
\end{array}\right.
$$

Besides, knowing also that when the accident occurs, the stock becomes $\tilde{S}_{T}^{(2)}=(1+\theta) S_{T}^{(3)}$ the expected marginal value of the waste stock at time $T$ is:

$\frac{\partial E W\left(S_{T}^{(2)}\right)}{\partial S_{T}^{(2)}}=B[1+\varepsilon] x^{*}\left[p U_{C}^{\prime}\left(x^{*}(1+\theta) S_{T}^{(3)},(1+\theta) S_{T}^{(3)}\right)+(1-p) U_{C}^{\prime}\left(x^{*} S_{T}^{(3)}, S_{T}^{(3)}\right)\right]$

\section{B Computing $\lambda_{0}^{(3)}$}

Setting $p=0$ and $x^{(3)}=x^{*}$ in the transversality condition (18) gives:

$$
-\frac{x^{*^{\eta_{1}}} S_{T}^{(3)^{\eta_{1}}}\left(S_{T}^{(3)}\right)^{\eta_{2}}}{\beta}-\frac{\lambda_{0}^{(3)}}{a \beta} e^{\left(\eta_{1}+\eta_{2}\right) r T}=B[1+\varepsilon] x^{*}\left[x^{*^{\eta_{1}}} S_{T}^{(3)^{\eta_{1}}}\left(S_{T}^{(3)}\right)^{\eta_{2}}\right]
$$

then, we obtain

$$
\begin{aligned}
\lambda_{0}^{(3)} & =-a \beta\left(B[1+\varepsilon] x^{*}+\frac{1}{\beta}\right)\left[x^{*^{\eta_{1}}} S_{0}^{\left(\eta_{1}+\eta_{2}\right)}\right] \\
& =-a \beta\left(B[1+\varepsilon] x^{*}+\frac{1}{\beta}\right) U_{C}^{\prime}\left(x^{*} S_{0}^{(3)}, S_{0}^{(3)}\right) \\
& =-a \beta\left(B[1+\varepsilon] x^{*}+\frac{1}{\beta}\right) U_{C}^{\prime}\left(x^{(3)} S_{0}^{(3)}, S_{0}^{(3)}\right)
\end{aligned}
$$

